Article

Toward Higher Sensitivity in Quantitative MALDI Imaging Mass Spectrometry of CNS Drugs Using a Nonpolar Matrix

Ignacy Rzagalinski, Borislav Kovacevic, Nadine Hainz,

Carola Meier, Thomas Tschernig, and Dietrich A. Volmer 


\title{
Toward Higher Sensitivity in Quantitative MALDI Imaging Mass Spectrometry of CNS Drugs Using a Nonpolar Matrix
}

\author{
Ignacy Rzagalinski ${ }^{1}$, Borislav Kovačević ${ }^{2}$, Nadine Hainz ${ }^{3}$, Carola Meier ${ }^{3}$, Thomas \\ Tschernig $^{3}$, Dietrich A. Volmer ${ }^{4}$ * \\ ${ }^{1}$ Institute of Bioanalytical Chemistry, Saarland University, 66123 Saarbrücken, Germany \\ ${ }^{2}$ Group for Computational Life Sciences, Ruđer Bošković Institute, 10000 Zagreb, Croatia \\ ${ }^{3}$ Institute of Anatomy and Cell Biology, Saarland University, 66421 Homburg, Germany \\ ${ }^{4}$ Department of Chemistry, Humboldt University of Berlin, 12489 Berlin, Germany
}

*To whom correspondence should be addressed:

Prof. Dr. Dietrich A. Volmer

Department of Chemistry

Humboldt University of Berlin

Brook-Taylor-Str. 2

12489 Berlin, Germany

Tel: +49 3020937588

Email: dietrich.volmer@hu-berlin.de 


\begin{abstract}
Tissue-specific ion suppression is an unavoidable matrix effect in MALDI mass spectrometry imaging (MSI), the negative impact of which on precision and accuracy in quantitative MALDI-MSI can be reduced to some extent by applying isotope internal standards for normalization and matrix-matched calibration routines. The detection sensitivity still suffers, however, often resulting in significant loss of signal for the investigated analytes. An MSI application considerably affected by this phenomenon is the quantitative spatial analysis of central nervous system (CNS) drugs. Most of these drugs are low molecular weight, lipophilic compounds, which exhibit inefficient desorption and ionization during MALDI using conventional polar acidic matrices (CHCA, DHB). Here, we present the application of the (2-[(2E)-3-(4-tert-butylphenyl)-2-methylprop-2-enylidene]malononitrile) matrix for high sensitivity imaging of CNS drugs in mouse brain sections. Since DCTB is usually described as electron-transfer matrix, we provide a rationale (i.e. computational calculations of gas-phase proton affinity and ionization energy) for an additional protontransfer ionization mechanism with this matrix. Furthermore, we compare the extent of signal suppression for five different CNS drugs when employing DCTB versus CHCA matrices. The results showed that the signal suppression was not only several times lower with DCTB than with CHCA, but also depended on the specific tissue investigated. Finally, we present the application of DCTB and ultra-high resolution Fourier-transform ion cyclotron resonance mass spectrometry to quantitative MALDI imaging of the anesthetic drug xylazine in mouse brain sections based on a linear matrix-matched calibration curve. DCTB afforded up to 100fold signal intensity improvement over CHCA when comparing representative single MSI pixels, and $>440$-fold for the averaged mass spectrum of the adjacent tissue sections.
\end{abstract}

Keywords: DCTB; 2-[(2E)-3-(4-tert-butylphenyl)-2-methylprop-2-enylidene]malononitrile; mass spectrometry imaging; MALDI; FTICR; CNS drugs; xylazine 


\section{INTRODUCTION}

Disorders affecting the central nervous system (CNS) are growing faster than any other disease, while progress in drug development in this area continues to be slow. ${ }^{1,2}$ This has many reasons including the high complexity of the brain, the frequent occurrence of side effects with CNS drugs, and above all, the prerequisite for drugs to cross the blood-brain barrier (BBB). ${ }^{3,4}$ The latter requirement has limited the current CNS drug portfolio predominantly to a small group of low molecular weight lipophilic compounds that can cross the BBB via transcellular passive diffusion (according to the Lipinski's rule of 5 ), ${ }^{5-7}$ even though new developments in carrier-mediated transport using liposomes ${ }^{8}$ or nanoparticles ${ }^{9,10}$ are of great interest and will potentially play a significant role in the longer perspective.

One of the most essential information at the early stages of drug discovery is the drug's and its metabolites' distribution in the whole body, which provides insight into the drug's toxicity as well as its ability to reach the therapeutically desired organ/tissue or target receptors. ${ }^{11,12}$ Measuring the drug's blood/plasma concentrations does not necessarily deliver adequate information about its organ/tissue distribution ${ }^{13}$. This is even relevant for the brain, as it is tightly isolated by the BBB; the drug distribution into the cerebrospinal fluid (CSF) is not a measure of BBB permeability into the brain parenchyma, but only through the bloodCSF barrier (BSCF). ${ }^{14}$ Consequently, analytical tools are urgently needed to quantitatively trace the drugs' spatial distributions in tissue sections, particularly brain sections for CNS drugs.

Over the last decade, mass spectrometry imaging (MSI) has gained wide acceptance as a label-free molecular imaging technique in drug distribution studies, providing considerable advantages over radiolabeled methods such as (quantitative) whole-body autoradiography $((\mathrm{Q}) \mathrm{WBA}) .{ }^{15,16}$ In addition, MSI allows for obtaining the information simultaneously from the parent drugs and its metabolites, as well as combining it with spatiotemporal changes in the metabolomic/lipidomic profiles. ${ }^{17}$ Another important advantage of MSI is that it can provide reliable quantitative information on the amount of drug in the examined sections. ${ }^{18-20}$ Of all MSI ionization techniques, matrix-assisted laser desorption/ionization (MALDI) is the most popular, ${ }^{21-25}$ particularly for imaging of pharmaceuticals. ${ }^{26,27}$ A number of recent review articles have summarized the state-of-the-art of the topic. ${ }^{28-32}$

One of the most promising applications for MSI is the measurement of the spatial distribution of xenobiotics in CNS tissue. ${ }^{33}$ A number of studies have described CNS spatial distribution of different drugs, ${ }^{34,35,44-46,36-43}$ narcotics, ${ }^{47-49}$ neurotoxin ${ }^{50}$ and positron emission 
tomography (PET) ligands. ${ }^{51}$ Two recent studies reported more sophisticated uses of MALDIMSI, including studying drug-drug interactions and their impact on the BBB permeability, ${ }^{52}$ and amyloid-binding molecules in an experimental model of Alzheimer's disease. ${ }^{53}$ Both examples provide an outlook to the future of MSI in the CNS pharmacology field. ${ }^{54}$

Although (MALDI-)MSI has proved its usefulness in pharmacology, several factors still limit its wider applicability to CNS drugs, which are predominantly linked to sensitivity issues. Firstly, MSI is a "sample volume limited" technique, in which the effective limits of detection and quantification will strongly depend on the employed pixel size (irradiated single spot area). ${ }^{55}$ This is further amplified by the aforementioned low permeability through the BBB that limits the amount of drug in the CNS parenchyma. Secondly, (MALDI-)MSI suffers significantly from the presence of tissue-specific ion suppression that cannot be entirely avoided since no separation step is implemented prior to ionization (in contrast to GC- or LCMS). ${ }^{56-58}$ While its negative impact on precision and accuracy in quantitative MALDI-MSI can be limited to some extent by applying isotope internal standards for normalization and matrix-matched calibration routines, ${ }^{19,20}$ the detection capabilities still suffer from this phenomenon, often resulting in a significant loss of signal for the investigated analytes. ${ }^{39,59,60}$ As a result, MSI of tissue in its native state (in situ) has to rely on alternative strategies. Among the simple strategies are changing the polarity of ionization as well as surface chemical treatments, such as washing the tissue with different solvents, for improving signal intensities for proteins, ${ }^{61}$ peptides, ${ }^{62}$ lipids, ${ }^{63}$ small metabolites ${ }^{64}$ and drugs. ${ }^{46,65}$ Another approach relied on using different salt additives that minimize negative ion suppression effects between different classes of lipids, as shown by Popkova and Schiller ${ }^{66}$ or Griffiths and Bunch $^{67}$ for MALDI-MS, as well as by Sugiyama et al. ${ }^{68}$ for MALDI-MSI. Other methods used improved matrix deposition techniques such as matrix-coating assisted by an electric field (MACEF) ${ }^{69}$ or matrix spraying by utilizing ultrasonic atomizing tablet and a simple mini-humidifier. ${ }^{70}$ Furthermore, improved selectivity toward selected compound classes by increasing ionization efficiency has been demonstrated for MALDI, by using alternative ionizing agents (e.g. ionizing cholesterol in a form of silver adducts) ${ }^{71}$, applying on-tissue derivatization reactions ${ }^{72}$ or even by simply utilizing different MALDI matrices such as, for example, nanoparticle-based inorganic matrices in surface-assisted laser desorption/ionization (SALDI) ${ }^{73}$ Surprisingly, despite the intensive research on new matrices, the most common method for matrix selection is still the empirical testing of the most popular (or readily available) compounds. Consequently, despite the aforementioned physicochemical properties of CNS drugs (small lipophilic molecules with low polar surface area and limited 
hydrogen bonding ${ }^{5-7}$ ), virtually all MALDI-MSI studies of these pharmaceuticals use the two most common polar and acidic matrices, $\alpha$-cyano-4-hydroxycinnamic acid $(\mathrm{CHCA})^{36,39,44,48,50,51,59,74}$ and 2,5-dihydroxybenzoic acid (DHB). ${ }^{35,38,49,52,53,39-43,45-47}$

In this study, we successfully applied the nonpolar DCTB (2-[(2E)-3-(4-tertbutylphenyl)-2-methylprop-2-enylidene]malononitrile) matrix for high sensitivity imaging of CNS drugs in mouse brain sections. DCTB has been frequently used as an electron-transfer matrix. We performed computational calculations of gas-phase proton affinity and ionization energy to explain the efficient, additional proton-transfer ionization mechanism with this matrix for five selected CNS drugs. Furthermore, using tissue extinction coefficients (TEC), we compared the extent of signal suppression for CNS drugs when employing DCTB versus CHCA matrices as well as tissue-specific ionization suppression. Finally, we applied DCTB for highly sensitive, quantitative MALDI imaging of the anesthetic drug xylazine within mouse brain sections using normalization to an isotope-labeled internal standard and a tissuematched calibration curve. 


\section{EXPERIMENTAL SECTION}

Chemicals and reagents. Xylazine, imipramine and clozapine were purchased from Santa Cruz Biotechnology (Heidelberg, Germany). Ketamine, clonidine, xylazine- $d_{6}$ (internal standard), a-cyano-4-hydroxycinnamic acid (CHCA), 2,5-dihydroxybenzoic acid (DHB), trans-2-[3-(4-tert-butylphenyl)-2-methyl-2-propenylidene]malononitrile (DCTB), methanol, acetonitrile, dichloromethane and standard microscopy glass slides were from Sigma-Aldrich (Steinheim, Germany). Rabbit brain was obtained from a local butcher store. Purified water was generated by a Millipore (Bedford, MA, USA) purification system.

Animals, tissue preparation and histological staining. C57BL/6 mice (12-week old) were purchased from Charles River (Sulzfeld, Germany). Xylazine/ketamine anesthesia was performed by injecting the following mixture: Rompun $(0.5 \mathrm{~mL})$, Ketavet $(1$ $\mathrm{mL})$ and $0.9 \% \mathrm{NaCl}(8.5 \mathrm{~mL})$; the dose was calculated per body weight $(0.1 \mathrm{~mL}$ per $10 \mathrm{~g}$ body weight). Deep isoflurane anesthesia (negative control) was carried out by inhalation of $5 \%$ isoflurane in oxygen. Animals were perfused with saline to remove the blood from the organism. Permission for the mouse perfusion was obtained from the local research ethics committee. The organs were dissected immediately after the sacrifice, snap-frozen in liquid nitrogen and stored at $-80^{\circ} \mathrm{C}$ until sample preparation. The coronal brain tissue sections were prepared at $14 \mu \mathrm{m}$ thickness using a Reichert Jung 2800 Frigocut cryostat microtome (Leica Microsystems, Wetzlar, Germany), thaw-mounted onto plain microscope glass slides and dried for $30 \mathrm{~min}$ in a vacuum desiccator. The tissues were stored at $-80^{\circ} \mathrm{C}$ for no longer than 2 d prior to MSI. After MALDI-MSI, the glass slides were washed with $70 \%$ ethanol to remove the matrix. The tissue sections were stained with regressive hematoxylin and eosin (H\&E) and scanned using an Olympus slide optical microscope with an UPLANSAPO 40x/0.90 objective (Olympus, Tokyo, Japan). Rabbit brain (for 'unified brain' preparation) was homogenized using a Potter-Elvehjem tissue grinder (Sartorius, Göttingen, Germany), transferred into 15 $\mathrm{mL}$ conical centrifuge tubes and snap-frozen in liquid nitrogen. The resulting tissue blocks were sectioned, mounted and dried at the same conditions as the native mouse brain tissues.

MALDI matrix and internal standard deposition. MALDI matrices and internal standard were homogenously sprayed onto the tissue sections using an automated home-built sprayer as previously described. ${ }^{75}$ Solutions of CHCA $\left(5 \mathrm{mg} / \mathrm{mL}\right.$ in $\mathrm{ACN} / \mathrm{H}_{2} \mathrm{O}$, $70 / 30[\mathrm{v} / \mathrm{v}])$, DCTB $(10 \mathrm{mg} / \mathrm{mL}$ in $\mathrm{DCM} / \mathrm{MeOH}, 50 / 50[\mathrm{v} / \mathrm{v}])$ and xylazine- $d_{6}(1 \mu \mathrm{M}$ in $\mathrm{MeOH})$ were freshly prepared prior to deposition. For TEC experiments, the mixture of 5 
CNS drugs in $\mathrm{MeOH}$ (at relatively high concentrations of $100 \mu \mathrm{M}$, to obtain a signal from all compounds with both matrices) was sprayed prior to matrix deposition with increasing flow rate in the following patterns: 2 layers at $20 \mu \mathrm{L} / \mathrm{min}, 2$ layers at $40 \mu \mathrm{L} / \mathrm{min}$ and 4 layers at 60 $\mu \mathrm{L} / \mathrm{min}$. For the final imaging experiments, internal standard (xylazine- $d_{6}$ ) was sprayed prior to the matrix deposition in 6 layers at $20 \mu \mathrm{L} / \mathrm{min}$. For both CHCA and DCTB matrices, 6 layers were sprayed with increasing flow rate in the following patterns: 2 layers at $20 \mu \mathrm{L} / \mathrm{min}$ and 4 layers at $40 \mu \mathrm{L} / \mathrm{min}$. The estimated amount of matrix added to the tissue (matrix density) was calculated at 0.0167 and $0.0334 \mathrm{mg} / \mathrm{mm}^{2}$ for CHCA and DCTB, respectively. In addition, in-depth visual inspection of the obtained MALDI matrix layers was performed using scanning electron microscopy (SEM) images, which revealed excellent homogeneity and reproducibility as well as crystal sizes down to $1 \mu \mathrm{m}$ for both CHCA and DCTB matrices (Figure S-1, SI).

Limits of detection and limits of quantification: Limits of detection (LOD) and quantification (LOQ) were adapted from generally-accepted guidelines for LCMS method development, to suit the quantitative MALDI-MSI data. Since a mass spectrum collected from a single MSI pixel corresponds to a single injection LC/MS run, the sampling of the entire single calibration spot provided sufficient averaging of multiple analyte measurements. Here, each calibration area provided 100-150 laser ablation spots, which far exceeded the number of technical replicates (=injections) of one calibration solution in LC/MS. LOD was obtained from replicate analysis of multiple blank spots ( $n=5$, of which every spot contained at least 100 laser shots = single mass spectra) and calculation of the standard deviation (SD). LOD was defined as the analyte concentration giving a signal equal to the blank signal plus $3 \times$ SD of the blank. LOQ was defined as the lowest concentration of a sample that can be quantified with acceptable precision (coefficient of variation, $\mathrm{CV} \leq 20 \%$ ) and bias $( \pm 20 \%)$. CV was measured within the single calibration spot (showing dispersion of drug signal intensity values of $>100$ single MSI pixels) and bias was calculated for the single spot from the calibration curve.

Mass spectrometry and data analysis. MALDI experiments were performed in positive ion mode on a Bruker (Bremen, Germany) 7 Tesla Solarix FTICR mass spectrometer, equipped with a dual ESI/MALDI ion source and Smartbeam II Nd:YAG (355 $\mathrm{nm})$ laser. MALDI imaging data were collected either in a full scan mode from $\mathrm{m} / \mathrm{z} 50$ to 1,000 (for TEC experiments) or in CASI (continuous accumulation of selected ions) mode with a $100 \mathrm{u}$ wide isolation window, set in the quadrupole, centered on $\mathrm{m} / \mathrm{z} 225$ with transient 
length of $1.0486 \mathrm{~s}$ and resolving power (FWHM) of $\sim 317,000$ at $\mathrm{m} / \mathrm{z} 220$. Internal mass calibration was performed using either a series of peaks originating from the MALDI matrix (TEC experiments) or a lock mass from the internal standard signal (xylazine imaging experiments). MSI pixel size settings were: $100 \mu \mathrm{m}$ for the final imaging of xylazine from dosed animals, which assured dense pixel deposition and avoided overlap between neighboring laser spots, and $150 \mu \mathrm{m}$ for TEC experiments (to reduce the time of the entire experiment). For all MALDI-MS and MALDI-MSI experiments, the laser was set to the "small" spot size and the repetition rate to $1 \mathrm{kHz}$. For experiments performed with CHCA and DHB, the laser power was set to $20 \%$ and the number of laser shots/pixel to 200 , while for the experiments with DCTB, the laser power was set to $15 \%$ and the number of laser shots/pixel to 50. MALDI experiments with standards were carried out by using dried-droplet sample preparation onto steel MALDI target plates (Bruker), and collecting and co-adding 16 individual transients for each mass spectrum from three MALDI spots, assuring correction for intra- and inter-spot variabilities. All MS/MS experiments were performed by isolation of precursor ions in the external quadrupole (isolation window: 5-10 u) and accumulation in the hexapole for collision-induced dissociation (CID) at varying collision energies (15-25 V). Data were processed and analyzed using the Bruker Data Analysis and FlexImaging software programs for single mass spectra and imaging data sets, respectively. For quantitative MALDI imaging of xylazine, a series of seven different calibration standard solutions was spotted onto the blank "unified brain" slices, followed by internal standard and DCTB matrix spraying. MALDI-MSI experiments were conducted using the same experimental conditions as for the native brain tissues. Finally, calibration curves were performed by extracting the imzML ${ }^{76}$ files from FlexImaging and processing with the open-source MSiReader software. ${ }^{77}$

Computational Experiments. Physicochemical properties $\left(\mathrm{p} K_{\mathrm{a}}\right.$ and $\left.\operatorname{cog} D\right)$ of five selected CNS drugs were predicted with ACD/PhysChem Suite (version 14.0, Advanced Chemistry Development, Toronto, ON, Canada, 2016). Calculations of gas phase deprotonation enthalpies (DPE) and gas phase proton affinities (PA) were performed utilizing B3LYP/6-311+G(2df,p)//B3LYP/6-31G(d) level of theory. This computational model has been confirmed as a reliable method for calculation of PA and DPE, giving values that were in good agreement with the experiment. ${ }^{78}$ However, since the accuracy of the B3LYP method is not satisfactory for calculation of ionization energies (IE), ${ }^{79}$ the MP2/6$31+\mathrm{G}(2 \mathrm{df}, \mathrm{p}) / / \mathrm{MP} 2 / 6-31 \mathrm{G}(\mathrm{d})$ approach was applied for this purpose. All calculations were performed with the Gaussian 09 program package. ${ }^{80}$ 


\section{RESULTS AND DISCUSSION}

\section{Rationale for Proton-transfer MALDI with DCTB Matrix. DCTB is} well-known for its efficient desorption/ionization capabilities at low laser fluences, which has been linked to its high molar absorption coefficient. ${ }^{81}$ Its application range is somewhat limited, predominantly for analysis of polymers ${ }^{82}$, fullerens ${ }^{83}$, organometallics $^{84}$ and more recently nanoparticles and nanoclusters ${ }^{85}$. DCTB's mode of action in these applications is that of an aprotic, electron-transfer (ET) secondary reaction matrix, delivering primarily radical ions in positive ion mode, or, when purposely forced, cationized molecules of the investigated compounds. This mechanism of action was previously investigated in detail by Wyatt et al. for different classes of compounds. ${ }^{86}$

Interestingly, experiments conducted in our laboratory revealed that DCTB appears equally suited as proton-transfer (PT) matrix, which prompted us to investigate a mechanistic rationale for this additional transfer mechanism. Since both current MALDI models (gas phase protonation and "Lucky Survivor" model) require an excess of protonated matrix ions for efficient MALDI analyte protonation, ${ }^{87}$ it was important to study the MALDI mass spectrum of pure DCTB in positive ion mode (Figure 1A). The spectrum exhibited two major ions, which were identified as the protonated molecule $[\mathrm{M}+\mathrm{H}]^{+}$and a radical cation after methyl loss $\left[\mathrm{M}-\mathrm{CH}_{3}\right]^{+\cdot}$. In addition, low intensity signals from the radical cation $\mathrm{M}^{+\cdot}$ and a somewhat unexpected $[\mathrm{M}-\mathrm{H}]^{+}$ion were also observed. The relative intensities of radical versus protonated DCTB signals depended on the laser fluence, with the latter more prominent at lower energies. Furthermore, as the secondary reactions occurring in the expanding MALDI plume are believed to occur under thermodynamic rather than kinetic control, $^{88}$ we also performed computational calculations of gas-phase proton affinities (PA). PA has been shown to determine the resulting MALDI mass spectra in positive ion mode as well as the ionization efficiencies observed for the chemical matrices. ${ }^{89}$ The low proton affinity of DCTB (see Figure 1), which is only slightly higher than that of CHCA and significantly lower than the two drugs studied here (xylazine and ketamine), suggests that secondary proton-transfer reactions between protonated matrix and neutral analyte are thermodynamically possible. These findings were confirmed by analyzing an equimolar mixture of the two drugs with DCTB, where protonated ketamine and xylazine signals were readily observed, the latter of which exhibited higher intensity due to the higher PA. Interestingly, the same experiments performed with two different MALDI matrices (CHCA 
versus DCTB) also revealed ion species of these drugs other than protonated molecules such as radical ions as well as sodium and/or potassium adducts. Their intensities, however, were always significantly lower than those of the protonated molecules (relative abundances, $\leq 1 \%$ ). Moreover, the relative intensity ratio of radical-to-protonated drug species was higher for DCTB than for CHCA. This suggests a mixed mechanism of DCTB-assisted laser desorption/ionization, with the proton-transfer clearly being the dominant pathway. Of note, the additionally calculated IE confirmed the less favorable nature of potential ET reactions between radical cation of matrix and neutral analyte. Moreover, calculation of DCTB gasphase acidities (deprotonation enthalpy, DPE $=1469 \mathrm{~kJ} / \mathrm{mol}$ versus $1382 \mathrm{~kJ} / \mathrm{mol}$ for CHCA and $1448 \mathrm{~kJ} / \mathrm{mol}$ for acetic acid) revealed the acidic character of the methyl group attached to the aliphatic chain of DCTB. This finding is in agreement with NMR data presented by Gabriel et al., ${ }^{90}$ who reported the highly acidic character of this methyl group, in contrast to the widely accepted aprotic description of DCTB. These data together with the abovementioned findings support an additional proton-transfer ionization mechanism of DCTB as MALDI matrix.

MALDI Matrix-dependent Tissue-specific Ion Suppression. To assess the usefulness of DCTB as nonpolar MALDI matrix for low molecular weight lipophilic CNS drugs, we selected five model compounds (Figure 2), representing different fields of neuropharmacological application: xylazine (veterinary tranquilizer/anesthetic), ketamine (drugs of abuse, but also promising as rapid and potent antidepressant), clonidine (anxiety disorder and withdrawal syndrome therapeutic), imipramine (tricyclic antidepressant), and clozapine (atypical antipsychotic treatment for schizophrenia). All selected compounds have molecular weights in the range of 200-400 $\mathrm{g} / \mathrm{mol}$ and are predominantly in their neutral forms at physiological $\mathrm{pH}$ of blood and brain; consequently, the calculated distribution coefficients $\operatorname{cog} D$ at $\mathrm{pH} 7.4$ are between 1 and 3 (Figure 2), thus confirming the liphophilic character at these conditions.

In the first set of experiments, we conducted MALDI-FTICR analyses. As can be seen in Figure 3A, CHCA matrix provided the highest signal intensities. The same drugs mixed with brain extract (obtained from isoflurane anesthetized mouse according to a modified protocol $^{91}$ ) to indicate the presence of potentially suppressing endogenous compounds exhibited the highest signal intensities when DCTB matrix was used (Figure 3B). This provided strong evidence for considerably lower signal suppression from endogenous brain 
tissue-related compounds with nonpolar DCTB matrix as compared to CHCA and DHB. DHB gave significantly lower signal intensities and also suffered from limitations of spatial resolving power due to the large crystals formed during spraying (see SEM images in Figure $\mathrm{S}-1, \mathrm{SI})$. In all further experiments, we therefore limited all further comparisons to CHCA versus DCTB.

To further validate these findings for MALDI-MSI, we employed the tissue extinction coefficient (TEC) technique developed by Stoeckli et al., ${ }^{59}$ which was later expanded by Hamm et al. ${ }^{39}$ Recently, Taylor et al. implemented TECs for systematic comparison of DESI and MALDI (with CHCA matrix)-related ion suppression of uniformly deposited olanzapine from heterogeneous transverse brain sections. ${ }^{60}$ For the TEC experiments, an equimolar mixture of five CNS drugs was sprayed onto the glass slide containing the three thawmounted negative control (isoflurane anesthetized) brain coronal sections, followed by MALDI-FTICR-MSI (see Experimental Section). As reference, the off-tissue glass region of interest was selected and imaged with the same experimental conditions. The final TEC values were calculated based on the relationship TEC $=I_{\mathrm{A} \text {,tissue }} / I_{\mathrm{A}, \text { ref }}$, where $I_{\mathrm{A}}$ are the averaged analyte ion currents on tissue and reference areas, $\mathrm{TEC}=1$ represents no suppression and $\mathrm{TEC}=0$ corresponds to total drug signal extinction. The results in Figure 4 show as much as 8fold less suppression with DCTB in comparison to CHCA and thus provide strong evidence for matrix-dependent, tissue-specific ionization suppression. Furthermore, closer investigation of the ion images of the five CNS drugs (Figure S-2, SI) revealed a heterogenous pattern of drug signals suppression (white versus grey matter), which was further underpinned by comparisons of mean mass spectra of the whole brain sections for the two matrices (see Figure S-3, SI).

In conclusion, while the current results may not provide a complete explanation of the improved performance of DCTB for MALDI imaging of the investigated CNS drugs from brain sections in comparison to CHCA, some initial positive conclusions can be drawn. DCTB clearly showed increased selectivity toward lipophilic CNS drugs as well as higher "resistance" to brain-specific ionization suppression phenomena from endogenous compounds such as salts, metabolites, lipids etc. as compared to CHCA. While the organic solvent used for dissolving DTCB may provide more efficient extraction of neutral analytes in comparison to CHCA, this does not explain the observed differences, because the lower signal suppression levels of DCTB were observed not only during MALDI-MSI of tissue sections but also from MALDI-MS analysis of bulk solutions containing the same interfering substances from the brain tissue extract. Unfortunately, it was not possible to fully clarify 
whether the observed effects were related to favorable desorption and gas-phase protonation of the investigated analytes or whether they result from physicochemical processes such as more efficient incorporation of non-ionized lipophilic drugs and/or less efficient incorporation of endogenous interfering metabolites/lipids into the non-polar DCTB matrix crystals. Further work on this topic is ongoing in the present authors' laboratory.

\section{Xylazine Spatial Distribution in Mouse Brain Sections using Ultra-} high Resolution FTICR-MSI. The utility of DCTB for MALDI-MSI of lipophilic CNS drugs was demonstrated using native brain tissues of drug-dosed animals (single dose anesthesia with a mixture of xylazine/ketamine, see Experimental Section). The intense signals detected from xylazine were assigned based on accurate mass measurements and ontissue collision-induced dissociation (CID) experiments by comparison to the drug standard and previously reported fragmentation patterns (Figure S-4, SI). ${ }^{92}$ We then conducted two MALDI-MSI experiments on consecutive coronal brain sections at spatial resolution of 100 $\mu \mathrm{m}$. As illustrated in Figure 5, tissue examined with CHCA matrix showed virtually no signals from xylazine, whereas tissue sprayed with DCTB matrix clearly revealed the spatial distribution of the drug (normalized to isotope-labeled internal standard). Since the examined tissue section clearly shows anatomical regions in the H\&E stain of the brain, the MS ion image of evenly sprayed xylazine- $d_{6}$ provided additional evidence for regional ion suppression, with the protonated xylazine molecule clearly less suppressed in the region of deep cerebral white matter as compared to the cerebral cortex, hippocampus, thalamus and hypothalamus (Figure 6).

Furthermore, to quantify the differences observed for the two matrices, single MSI pixel mass spectra from representative regions of the highest xylazine abundance were compared, showing more than 100-fold higher signal intensity obtained with DCTB over CHCA. Moreover, when the average mass spectra from the whole examined tissue sections were compared, $>440$-fold signal improvement was achieved with DCTB versus CHCA. Importantly, the ultra-high resolving power of the Fourier-transform ion cyclotron resonance mass spectrometer used here played a significant role in this comparison, since a DCTBderived interfering ion signal was visible only $0.003 \mathrm{u}$ adjacent to protonated xylazine. This interference had practical implications on the direct on-tissue quantification of xylazine (see next section). In addition to xylazine, we also interrogated the MSI data sets for the second administered anesthetic, ketamine as well as for potential metabolites of both drugs. As shown 
in the previous section, ketamine exhibited much lower ionization efficiency in comparison to xylazine and was therefore not detected in the imaging experiments. Equally, we did not observe any of the reported biotransformation products of xylazine ${ }^{92}$ or ketamine. ${ }^{93}$

On-tissue Quantification of Xylazine. Since most pharmaceutical MALDIMSI studies require absolute quantification of the investigated compounds directly from the tissue surfaces, we also implemented the DCTB matrix for this purpose. Obtaining reliable quantitative results with MALDI-MSI requires normalization to isotopically-labeled internal standard (xylazine- $d_{6}$ ) and matrix-matched calibration routines. The best results for the latter are usually obtained by using either the sophisticated "mimetic tissue" model or a simpler "on-tissue" approach. ${ }^{20}$ Here, we combined both strategies (the workflow is presented in Figure S-5, SI). Briefly, rabbit brain was homogenized and snap-frozen in liquid nitrogen for the best possible emulation of the original intact tissue morphology, as previously reported by Jadoul et al. ${ }^{94}$ The prepared blocks of "unified brain" tissue (containing a representation of the interfering endogenous compounds from different anatomical brain regions) were then cut with the cryomicrotome and served as large and convenient blank sections for the fast "ontissue" spiking approach.

This approach generated linear relationships (coefficients of determination, $R^{2}=$ 0.996) over a wide concentration range of the calibration curve (almost three orders of magnitude, see Figure S-5, SI). The limits of detection (LOD, estimated from multiple blank measurements) and limits of quantification LOQ, (based on a precision of the measurements of $20 \%$ or better, and calculated bias values for the lowest concentrated calibration solution within $80-120 \%$ ) were $0.629 \mu \mathrm{g} / \mathrm{g}$ and $3.14 \mu \mathrm{g} / \mathrm{g}$, respectively (assuming average brain density of $\left.1.027 \mathrm{~g} / \mathrm{cm}^{3}\right) .{ }^{95}$ Finally, the average absolute concentration of xylazine across the mouse brain coronal section illustrated in Figure 5-B was calculated to be $21.75 \pm 0.41$

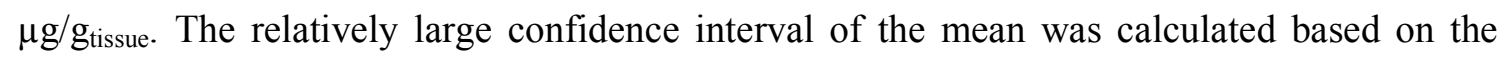
standard deviation of all scans (scan number, $n=4255$ ), averaged across the whole tissue section; therefore, it reflects the heterogeneity of xylazine distribution in the brain section. 


\section{CONCLUSIONS}

The primary aim of this study was the application of the non-polar DCTB compound as MALDI matrix for high sensitivity imaging of CNS drugs in mouse brain sections. Based on five selected neuropharmaceuticals, which all fulfilled the requirements for crossing the blood-brain barrier via transcellular passive diffusion (i.e., Lipinski's rule of 5), we demonstrated that DCTB can be successfully used for high sensitive MALDI mass spectral imaging of these compounds from murine brain sections using an ultra-high resolution Fourier-transform ion cyclotron resonance (FTICR) platform. We provided a theoretical and experimental rationale for an additional proton-transfer ionization mechanism of the DCTB matrix, even though DCTB is usually considered an electron-transfer matrix. We also investigated tissue specific ion suppression for DCTB versus the conventional polar and acidic CHCA matrix, based on tissue extinction coefficients (TEC). These experiments showed multi-fold lower signal suppression for the drugs using DCTB than CHCA. Furthermore, we applied DCTB for quantitative imaging of a commonly used veterinary anesthetic drug, xylazine from mouse coronal brain sections. Compared to CHCA, the data showed significant signal intensity improvements by as much as 100 -fold for representative single MSI pixels of two serial sections and more than 440-fold for an average mass spectrum from the whole adjacent tissue sections. Finally, the application of tissue-matched standardization allowed for excellent linearity of the calibration curve over a wide concentration range with satisfactory precision.

The use of the DCTB matrix was not without challenges, however, including difficulties linked to the low melting point $\left(\sim 130{ }^{\circ} \mathrm{C}\right.$ versus $\sim 249{ }^{\circ} \mathrm{C}$ for $\left.\mathrm{CHCA}\right)$, i.e. limited stability under high vacuum conditions (which was overcome by normalization to homogenously sprayed internal standard) and the "volcano" type ablation profiles, which can constitute a challenge for higher spatial resolutions than used here. We did not observe any formation of adducts between DCTB and drugs as previously described by Lou et al. ${ }^{96}$

Our future work will focus on improving the DCTB matrix solubility and stability under high vacuum conditions. Other work currently in progress includes a detailed investigation of the tissue-specific ionization suppression of different drugs when using different MALDI matrices, which will further improve the detection capabilities of MALDIMSI for other pharmaceutical drugs. 


\section{ASSOCIATED CONTENT}

Supporting Information is available free of charge on the ACS Publications website.

SEM of sprayed MALDI matrices; MS ion images and mean spectra from TEC experiments; Mean mass spectra obtained from TEC experiments of mouse brain coronal sections; on-tissue identification of xylazine; on-tissue quantification workflow and calibration curves.

\section{AUTHOR INFORMATION}

\section{Corresponding author:}

*E-mail: dietrich.volmer@hu-berlin.de

Notes

The authors declare no competing financial interest.

\section{ACKNOWLEDGMENTS}

D.A.V. acknowledges research support by the German Research Foundation (FTICR-MS Facility, INST 256/356-1). The authors thank Tim Salbert (ACD/Labs) for the use of the Percepta software, Pascal Schorr (Humboldt University Berlin) for the rabbit brain preparations, Sylvia Kuhn (Saarland University) for SEM measurements and Alexander Grißmer (Saarland University Medical Center) for staining and light microscopy experiments. 


\section{REFERENCES}

(1) Pangalos, M. N.; Schechter, L. E.; Hurko, O. Drug Development for CNS Disorders: Strategies for Balancing Risk and Reducing Attrition. Nat. Rev. Drug Discov. 2007, 6 (7), 521-532.

(2) Pardridge, W. M. Blood-Brain Barrier Delivery. Drug Discov. Today 2007, 12 (1-2), 54-61.

(3) Pardridge, W. M. Drug Targeting to the Brain. Pharm. Res. 2007, 24 (9), 1733-1744.

(4) Palmer, A. M.; Alavijeh, M. S. Foundation Review: Translational CNS Medicines Research. Drug Discov. Today 2012, 17 (19-20), 1068-1078.

(5) Lipinski, C. A. Drug-like Properties and the Causes of Poor Solubility and Poor Permeability. J. Pharmacol. Toxicol. Methods 2000, 44 (1), 235-249.

(6) Mikitsh, J. L.; Chacko, A. M. Pathways for Small Molecule Delivery to the Central Nervous System across the Blood-Brain Barrier. Perspect. Medicin. Chem. 2014, No. $6,11-24$.

(7) Pardridge, W. M. Drug Transport across the Blood-Brain Barrier. J. Cereb. Blood Flow Metab. 2012, 32 (11), 1959-1972.

(8) Lai, F.; Fadda, A. M.; Sinico, C. Liposomes for Brain Delivery. Expert Opin. Drug Deliv. 2013, 10 (7), 1003-1022.

(9) Wohlfart, S.; Gelperina, S.; Kreuter, J. Transport of Drugs across the Blood-Brain Barrier by Nanoparticles. J. Control. Release 2012, 161 (2), 264-273.

(10) Saraiva, C.; Praça, C.; Ferreira, R.; Santos, T.; Ferreira, L.; Bernardino, L. Nanoparticle-Mediated Brain Drug Delivery: Overcoming Blood-Brain Barrier to Treat Neurodegenerative Diseases. J. Control. Release 2016, 235, 34-47.

(11) Rudin, M.; Weissleder, R. Molecular Imaging in Drug Discovery and Development. Nat. Rev. Drug Discov. 2003, 2 (2), 123-131.

(12) Willmann, J. K.; van Bruggen, N.; Dinkelborg, L. M.; Gambhir, S. S. Molecular Imaging in Drug Development. Nat. Rev. Drug Discov. 2008, 7 (7), 591-607.

(13) Pellegatti, M.; Pagliarusco, S. Drug and Metabolite Concentrations in Tissues in Relationship to Tissue Adverse Findings: A Review. Expert Opin. Drug Metab. Toxicol. 2011, 7 (2), 137-146.

(14) Pardridge, W. M. CSF, Blood-Brain Barrier, and Brain Drug Delivery. Expert Opin. Drug Deliv. 2016, 13 (7), 963-975. 
(15) Solon, E. G.; Schweitzer, A.; Stoeckli, M.; Prideaux, B. Autoradiography, MALDIMS, and SIMS-MS Imaging in Pharmaceutical Discovery and Development. AAPS J. 2010, 12 (1), 11-26.

(16) Cobice, D. F.; Goodwin, R. J. A.; Andren, P. E.; Nilsson, A.; Mackay, C. L.; Andrew, R. Future Technology Insight: Mass Spectrometry Imaging as a Tool in Drug Research and Development. Br. J. Pharmacol. 2015, 172 (13), 3266-3283.

(17) Sugiura, Y.; Setou, M. Imaging Mass Spectrometry for Visualization of Drug and Endogenous Metabolite Distribution: Toward in Situ Pharmacometabolomes. J. Neuroimmune Pharmacol. 2010, 5 (1), 31-43.

(18) Sun, N.; Walch, A. Qualitative and Quantitative Mass Spectrometry Imaging of Drugs and Metabolites in Tissue at Therapeutic Levels. Histochem. Cell Biol. 2013, 140 (2), 93-104.

(19) Ellis, S. R.; Bruinen, A. L.; Heeren, R. M. A. A Critical Evaluation of the Current State-of-the-Art in Quantitative Imaging Mass Spectrometry. Anal. Bioanal. Chem. 2014, 406 (5), 1275-1289.

(20) Rzagalinski, I.; Volmer, D. A. Quantification of Low Molecular Weight Compounds by MALDI Imaging Mass Spectrometry - A Tutorial Review. Biochim. Biophys. Acta Proteins Proteomics 2017, 1865 (7), 726-739.

(21) Chughtai, K.; Heeren, R. M. A. Mass Spectrometric Imaging for Biomedical Tissue Analysis. Chem. Rev. 2010, 110 (5), 3237-3277.

(22) Norris, J. L.; Caprioli, R. M. Analysis of Tissue Specimens by Matrix-Assisted Laser Desorption/Ionization Imaging Mass Spectrometry in Biological and Clinical Research. Chem. Rev. 2013, 113 (4), 2309-2342.

(23) Spengler, B. Mass Spectrometry Imaging of Biomolecular Information. Anal. Chem. 2015, 87 (1), 64-82.

(24) Bodzon $\square$ Kulakowska, A.; Suder, P. Imaging Mass Spectrometry: Instrumentation, Applications, and Combination with Other Visualization Techniques. Mass Spectrom. Rev. 2016, 35 (1), 147-169.

(25) Palmer, A.; Trede, D.; Alexandrov, T. Where Imaging Mass Spectrometry Stands: Here Are the Numbers. Metabolomics 2016, 12 (6), 107.

(26) Karlsson, O.; Hanrieder, J. Imaging Mass Spectrometry in Drug Development and Toxicology. Arch. Toxicol. 2017, 91 (6), 2283-2294.

(27) Swales, J. G.; Hamm, G.; Clench, M. R.; Goodwin, R. J. A. Mass Spectrometry Imaging and Its Application in Pharmaceutical Research and Development: A Concise 
Review. Int. J. Mass Spectrom. 2018, DOI: 10.1016/j.ijms.2018.02.007.

(28) Goodwin, R. J.; Pitt, A. R. Mass Spectrometry Imaging of Pharmacological Compounds in Tissue Sections. Bioanalysis 2010, 2 (2), 279-293.

(29) Greer, T.; Sturm, R.; Li, L. Mass Spectrometry Imaging for Drugs and Metabolites. $J$. Proteomics 2011, 74 (12), 2617-2631.

(30) Prideaux, B.; Stoeckli, M. Mass Spectrometry Imaging for Drug Distribution Studies. J. Proteomics 2012, 75 (16), 4999-5013.

(31) Hochart, G.; Hamm, G.; Stauber, J. Label-Free MS Imaging from Drug Discovery to Preclinical Development. Bioanalysis 2014, 6 (20), 2775-2788.

(32) Nilsson, A.; Goodwin, R. J. A.; Shariatgorji, M.; Vallianatou, T.; Webborn, P. J. H.; Andren, P. E. Mass Spectrometry Imaging in Drug Development. Anal. Chem. 2015, 87 (3), 1437-1455.

(33) Shariatgorji, M.; Svenningsson, P.; Andrén, P. E. Mass Spectrometry Imaging, an Emerging Technology in Neuropsychopharmacology. Neuropsychopharmacology 2014, 39 (1), 34-39.

(34) Hsieh, Y.; Casale, R.; Fukuda, E.; Chen, J.; Knemeyer, I.; Wingate, J.; Morrison, R.; Korfmacher, W. Matrix-Assisted Laser Desorption/Ionization Imaging Mass Spectrometry for Direct Measurement of Clozapine in Rat Brain Tissue. Rapid Commun. Mass Spectrom. 2006, 20 (6), 965-972.

(35) Li, F.; Hsieh, Y.; Kang, L.; Sondey, C.; Lachowicz, J.; Korfmacher, W. A. MALDITandem Mass Spectrometry Imaging of Astemizole and Its Primary Metabolite in Rat Brain Sections. Bioanalysis 2009, 1 (2), 299-307.

(36) Shin, Y. G.; Dong, T.; Chou, B.; Menghrajani, K. Determination of Loperamide in Mdr1a/1b Knock-out Mouse Brain Tissue Using Matrix-Assisted Laser Desorption/Ionization Mass Spectrometry and Comparison with Quantitative Electrospray-Triple Quadrupole Mass Spectrometry Analysis. Arch. Pharm. Res. 2011, 34 (11), 1983-1988.

(37) Shanta, S. R.; Kim, T. Y.; Hong, J. H.; Lee, J. H.; Shin, C. Y.; Kim, K.-H.; Kim, Y. H.; Kim, S. K.; Kim, K. P. A New Combination MALDI Matrix for Small Molecule Analysis: Application to Imaging Mass Spectrometry for Drugs and Metabolites. Analyst 2012, 137 (24), 5757.

(38) Källback, P.; Shariatgorji, M.; Nilsson, A.; Andrén, P. E. Novel Mass Spectrometry Imaging Software Assisting Labeled Normalization and Quantitation of Drugs and Neuropeptides Directly in Tissue Sections. J. Proteomics 2012, 75 (16), 4941-4951. 
(39) Hamm, G.; Bonnel, D.; Legouffe, R.; Pamelard, F.; Delbos, J. M.; Bouzom, F.; Stauber, J. Quantitative Mass Spectrometry Imaging of Propranolol and Olanzapine Using Tissue Extinction Calculation as Normalization Factor. J. Proteomics 2012, 75 (16), 4952-4961.

(40) Castellino, S.; Groseclose, M. R.; Sigafoos, J.; Wagner, D.; De Serres, M.; Polli, J. W.; Romach, E.; Myer, J.; Hamilton, B. Central Nervous System Disposition and Metabolism of Fosdevirine (GSK2248761), a Non-Nucleoside Reverse Transcriptase Inhibitor: An LC-MS and Matrix-Assisted Laser Desorption/Ionization Imaging MS Investigation into Central Nervous System Toxicity. Chem. Res. Toxicol. 2013, 26 (2), 241-251.

(41) Salphati, L.; Shahidi-Latham, S.; Quiason, C.; Barck, K.; Nishimura, M.; Alicke, B.; Pang, J.; Carano, R. A.; Olivero, A. G.; Phillips, H. S. Distribution of the Phosphatidylinositol 3-Kinase Inhibitors Pictilisib (GDC-0941) and GNE-317 in U87 and GS2 Intracranial Glioblastoma Models - Assessment by Matrix-Assisted Laser Desorption Ionization Imaging. Drug Metab. Dispos. 2014, 42 (7), 1110-1116.

(42) Swales, J. G.; Tucker, J. W.; Strittmatter, N.; Nilsson, A.; Cobice, D.; Clench, M. R.; Mackay, C. L.; Andren, P. E.; Takáts, Z.; Webborn, P. J. H.; et al. Mass Spectrometry Imaging of Cassette-Dosed Drugs for Higher Throughput Pharmacokinetic and Biodistribution Analysis. Anal. Chem. 2014, 86 (16), 8473-8480.

(43) Liu, X.; Ide, J. L.; Norton, I.; Marchionni, M. A.; Ebling, M. C.; Wang, L. Y.; Davis, E.; Sauvageot, C. M.; Kesari, S.; Kellersberger, K. A.; et al. Molecular Imaging of Drug Transit through the Blood-Brain Barrier with MALDI Mass Spectrometry Imaging. Sci. Rep. 2013, 3, 1-7.

(44) Aikawa, H.; Hayashi, M.; Ryu, S.; Yamashita, M.; Ohtsuka, N.; Nishidate, M.; Fujiwara, Y.; Hamada, A. Visualizing Spatial Distribution of Alectinib in Murine Brain Using Quantitative Mass Spectrometry Imaging. Sci. Rep. 2016, 6 (October 2015), 23749.

(45) Tanaka, Y.; Hirata, M.; Shinonome, S.; Torii, M.; Nezasa, K. I.; Tanaka, H. Distribution Analysis of Epertinib in Brain Metastasis of HER2-Positive Breast Cancer by Imaging Mass Spectrometry and Prospect for Antitumor Activity. Sci. Rep. 2018, 8 (1), 1-12.

(46) Shariatgorji, M.; Källback, P.; Gustavsson, L.; Schintu, N.; Svenningsson, P.; Goodwin, R. J. A.; Andren, P. E. Controlled-PH Tissue Cleanup Protocol for Signal Enhancement of Small Molecule Drugs Analyzed by MALDI-MS Imaging. Anal. 
Chem. 2012, 84 (10), 4603-4607.

(47) Reich, R. F.; Cudzilo, K.; Levisky, J. A.; Yost, R. A. Quantitative MALDI-MSn Analysis of Cocaine in the Autopsied Brain of a Human Cocaine User Employing a Wide Isolation Window and Internal Standards. J. Am. Soc. Mass Spectrom. 2010, 21 (4), 564-571.

(48) Kuwayama, K.; Tsujikawa, K.; Miyaguchi, H.; Kanamori, T.; Iwata, Y. T.; Inoue, H. Distribution Measurements of 3,4-Methylenedioxymethamphetamine and Its Metabolites in Organs by Matrix-Assisted Laser Desorption/Ionization Imaging Mass Spectrometry Using an Automatic Matrix Spraying System with an Air Brush and a Turntable. Anal. Bioanal. Chem. 2012, 404 (6-7), 1823-1830.

(49) Pirman, D. A.; Reich, R. F.; Kiss, A.; Heeren, R. M. A.; Yost, R. A. Quantitative MALDI Tandem Mass Spectrometric Imaging of Cocaine from Brain Tissue with a Deuterated Internal Standard. Anal. Chem. 2013, 85 (2), 1081-1089.

(50) Kadar, H.; Le Douaron, G.; Amar, M.; Ferrié, L.; Figadère, B.; Touboul, D.; Brunelle, A.; Raisman-Vozari, R. MALDI Mass Spectrometry Imaging of 1-Methyl-4Phenylpyridinium (MPP+) in Mouse Brain. Neurotox. Res. 2014, 25 (1), 135-145.

(51) Goodwin, R. J. A.; MacKay, C. L.; Nilsson, A.; Harrison, D. J.; Farde, L.; Andren, P. E.; Iverson, S. L. Qualitative and Quantitative MALDI Imaging of the Positron Emission Tomography Ligands Raclopride (a D2 Dopamine Antagonist) and SCH 23390 (a D1 Dopamine Antagonist) in Rat Brain Tissue Sections Using a Solvent-Free Dry Matrix Application Method. Anal. Chem. 2011, 83 (24), 9694-9701.

(52) Vallianatou, T.; Strittmatter, N.; Nilsson, A.; Shariatgorji, M.; Hamm, G.; Pereira, M.; Källback, P.; Svenningsson, P.; Karlgren, M.; Goodwin, R. J. A.; et al. A Mass Spectrometry Imaging Approach for Investigating How Drug-Drug Interactions Influence Drug Blood-Brain Barrier Permeability. Neuroimage 2018, 172 (September 2017), 808-816.

(53) McClure, R. A.; Chumbley, C. W.; Reyzer, M. L.; Wilson, K.; Caprioli, R. M.; Gore, J. C.; Pham, W. Identification of Promethazine as an Amyloid-Binding Molecule Using a Fluorescence High-Throughput Assay and MALDI Imaging Mass Spectrometry. NeuroImage Clin. 2013, 2 (1), 620-629.

(54) Goodwin, R. J.; Webborn, P. J. Future Directions of Imaging MS in Pharmaceutical R\&D. Bioanalysis 2015, 7 (20), 2667-2673.

(55) Castellino, S.; Groseclose, M. R.; Wagner, D. MALDI Imaging Mass Spectrometry: Bridging Biology and Chemistry in Drug Development. Bioanalysis 2011, 3 (21), 
$2427-2441$.

(56) Annesley, T. M. Ion Suppression in Mass Spectrometry. Clin. Chem. 2003, 49 (7), $1041-1044$.

(57) Jessome, L. L.; Volmer, D. A. Ion Suppression: A Major Concern in Mass Spectrometry. LCGC North Am. 2006, 24 (5), 498-510.

(58) Furey, A.; Moriarty, M.; Bane, V.; Kinsella, B.; Lehane, M. Ion Suppression; A Critical Review on Causes, Evaluation, Prevention and Applications. Talanta 2013, $115,104-122$.

(59) Stoeckli, M.; Staab, D.; Schweitzer, A. Compound and Metabolite Distribution Measured by MALDI Mass Spectrometric Imaging in Whole-Body Tissue Sections. Int. J. Mass Spectrom. 2007, 260 (2-3), 195-202.

(60) Taylor, A.; Dexter, A.; Bunch, J. Exploring Ion Suppression in Mass Spectrometry Imaging of a Heterogeneous Tissue. Anal. Chem. 2018, 90, 5637-5645.

(61) Seeley, E. H.; Oppenheimer, S. R.; Mi, D.; Chaurand, P.; Caprioli, R. M. Enhancement of Protein Sensitivity for MALDI Imaging Mass Spectrometry After Chemical Treatment of Tissue Sections. J. Am. Soc. Mass Spectrom. 2008, 19 (8), 1069-1077.

(62) Andersson, M.; Groseclose, M. R.; Deutch, A. Y.; Caprioli, R. M. Imaging Mass Spectrometry of Proteins and Peptides: 3D Volume Reconstruction. Nat. Methods 2008, 5 (1), 101-108.

(63) Wang, H. Y. J.; Wu, H. W.; Tsai, P. J.; Liu, C. Bin. MALDI-Mass Spectrometry Imaging of Desalted Rat Brain Sections Reveals Ischemia-Mediated Changes of Lipids. Anal. Bioanal. Chem. 2012, 404 (1), 113-124.

(64) Yang, H.; Ji, W.; Guan, M.; Li, S.; Zhang, Y.; Zhao, Z.; Mao, L. Organic Washes of Tissue Sections for Comprehensive Analysis of Small Molecule Metabolites by MALDI MS Imaging of Rat Brain Following Status Epilepticus. Metabolomics 2018, $14(4), 1-12$.

(65) Song, X.; Luo, Z.; Li, X.; Li, T.; Wang, Z.; Sun, C.; Huang, L.; Xie, P.; Liu, X.; He, J.; et al. In Situ Hydrogel Conditioning of Tissue Samples to Enhance the Drug's Sensitivity in Ambient Mass Spectrometry Imaging. Anal. Chem. 2017, 89 (12), 63186323.

(66) Popkova, Y.; Schiller, J. Addition of $\mathrm{CsCl}$ Reduces Ion Suppression Effects in the Matrix-Assisted Laser Desorption/Ionization Mass Spectra of Triacylglycerol/Phosphatidylcholine Mixtures and Adipose Tissue Extracts. Rapid Commun. Mass Spectrom. 2017, 31 (5), 411-418. 
(67) Griffiths, R. L.; Bunch, J. A Survey of Useful Salt Additives in Matrix-Assisted Laser Desorption/Ionization Mass Spectrometry and Tandem Mass Spectrometry of Lipids: Introducing Nitrates for Improved Analysis. Rapid Commun. Mass Spectrom. 2012, 26 (13), 1557-1566.

(68) Sugiyama, E.; Masaki, N.; Matsushita, S.; Setou, M. Ammonium Sulfate Improves Detection of Hydrophilic Quaternary Ammonium Compounds through Decreased Ion Suppression in Matrix-Assisted Laser Desorption/Ionization Imaging Mass Spectrometry. Anal. Chem. 2015, 87 (22), 11176-11181.

(69) Wang, X.; Han, J.; Yang, J.; Pan, J.; Borchers, C. H. Matrix Coating Assisted by an Electric Field (MCAEF) for Enhanced Tissue Imaging by MALDI-MS. Chem. Sci. 2015, 6 (1), 729-738.

(70) Huang, X.; Zhan, L.; Sun, J.; Xue, J.; Liu, H.; Xiong, C.; Nie, Z. Utilizing a MiniHumidifier to Deposit Matrix for MALDI Imaging. Anal. Chem. 2018, 90 (14), 83098313.

(71) Dufresne, M.; Thomas, A.; Breault-Turcot, J.; Masson, J.-F.; Chaurand, P. SilverAssisted Laser Desorption Ionization For High Spatial Resolution Imaging Mass Spectrometry of Olefins from Thin Tissue Sections. Anal. Chem. 2013, 85 (6), 3318 3324.

(72) Esteve, C.; Tolner, E. A.; Shyti, R.; van den Maagdenberg, A. M. J. M.; McDonnell, L. A. Mass Spectrometry Imaging of Amino Neurotransmitters: A Comparison of Derivatization Methods and Application in Mouse Brain Tissue. Metabolomics 2016, $12(2), 1-9$.

(73) Lin, Z.; Cai, Z. Negative Ion Laser Desorption/Ionization Time-of-Flight Mass Spectrometric Analysis of Small Molecules by Using Nanostructured Substrate as Matrices. Mass Spectrom. Rev. 2018, No. February 2017, 1-16.

(74) Wang, H. Y. J.; Jackson, S. N.; McEuen, J.; Woods, A. S. Localization and Analyses of Small Drug Molecules in Rat Brain Tissue Sections. Anal. Chem. 2005, 77 (20), 66826686.

(75) Rzagalinski, I.; Hainz, N.; Meier, C.; Tschernig, T.; Volmer, D. A. MALDI Mass Spectral Imaging of Bile Acids Observed as Deprotonated Molecules and ProtonBound Dimers from Mouse Liver Sections. J. Am. Soc. Mass Spectrom 2018, 29 (4), $711-722$.

(76) Schramm, T.; Hester, A.; Klinkert, I.; Both, J. P.; Heeren, R. M. A.; Brunelle, A.; Laprévote, O.; Desbenoit, N.; Robbe, M. F.; Stoeckli, M.; et al. ImzML - A Common 
Data Format for the Flexible Exchange and Processing of Mass Spectrometry Imaging Data. J. Proteomics 2012, 75 (16), 5106-5110.

(77) Bokhart, M. T.; Nazari, M.; Garrard, K. P.; Muddiman, D. C. MSiReader v1.0: Evolving Open-Source Mass Spectrometry Imaging Software for Targeted and Untargeted Analyses. J. Am. Soc. Mass Spectrom. 2018, 29 (1), 8-16.

(78) Toomsalu, E.; Koppel, I. A.; Burk, P. Critical Test of Some Computational Chemistry Methods for Prediction of Gas-Phase Acidities and Basicities. J. Chem. Theory Comput. 2013, 9 (9), 3947-3958.

(79) Rayne, S.; Forest, K. Benchmarking Semiempirical, Hartree-Fock, DFT, and MP2 Methods against the Ionization Energies and Electron Affinities of Short-through Long-Chain [n] Acenes and [n] Phenacenes. Can. J. Chem. 2016, 94 (3), 251-258.

(80) Frisch, M.; Trucks, G. W.; Schlegel, H. B.; Scuseria, G. E.; Robb, M. A.; Cheeseman, J. R.; Scalmani, G.; Barone, V.; Mennucci, B.; Petersson, Ga. Gaussian 09, Revision A.02,. Gaussian Inc., Wallingford CT 2016.

(81) Ulmer, L.; Mattay, J.; Torres-Garcia, H.; Luftmann, H. The Use of 2-[(2E)-3-(4-TertButylphenyl)-2- Methylprop-2-Enylidene]Malononitrile as a Matrix for MatrixAssisted Laser Desorption/Ionization Mass Spectrometry. Eur. J. Mass Spectrom. 2000, $6(1), 49$.

(82) Mizukado, J.; Sato, H.; Chen, L.; Suzuki, Y.; Yamane, S.; Aoyama, Y.; Suda, H. HighResolution MALDI-TOF MS Study on Analysis of Low-Molecular-Weight Products from Photo-Oxidation of Poly(3-Hexylthiophene). J. Mass Spectrom. 2015, 50 (8), 1006-1012.

(83) Markov, V. Y.; Borschevsky, A. Y.; Sidorov, L. N. MALDI Mass Spectrometry of Fullerene Derivatives. Int. J. Mass Spectrom. 2012, 325-327, 100-112.

(84) Bergman, N.; Thapper, A.; Styring, S.; Bergquist, J.; Shevchenko, D. Quantitative Determination of the $\mathrm{Ru}(\mathrm{Bpy}) 32+$ Cation in Photochemical Reactions by MatrixAssisted Laser Desorption/Ionization Time-of-Flight Mass Spectrometry. Anal. Methods 2014, 6 (21), 8513-8518.

(85) Kumara, C.; Dass, A. Au329(SR)84 Nanomolecules: Compositional Assignment of the 76.3 KDa Plasmonic Faradaurates. Anal. Chem. 2014, 86 (9), 4227-4232.

(86) Wyatt, M. F.; Stein, B. K.; Brenton, A. G. Characterization of Various Analytes Using Matrix Assisted Laser Desorption/Ionization Time of Flight Mass Spectrometry and 2[(2E)-3-(4-Tert-Butylphenyl)-2-Methylprop-2-Enylidene]Malononitrile Matrix. Anal. Chem. 2006, 78 (1), 199-206. 
(87) Jaskolla, T. W.; Karas, M. Compelling Evidence for Lucky Survivor and Gas Phase Protonation: The Unified MALDI Analyte Protonation Mechanism. J. Am. Soc. Mass Spectrom. 2011, 22 (6), 976-988.

(88) Knochenmuss, R. Ion Formation Mechanisms in UV-MALDI. Analyst 2006, 131 (9), 966.

(89) Soltwisch, J.; Jaskolla, T. W.; Hillenkamp, F.; Karas, M.; Dreisewerd, K. Ion Yields in UV-MALDI Mass Spectrometry as a Function of Excitation Laser Wavelength and Optical and Physico-Chemical Properties of Classical and Halogen-Substituted MALDI Matrixes. Anal. Chem. 2012, 84 (15), 6567-6576.

(90) Gabriel, S. J.; Pfeifer, D.; Schwarzinger, C.; Panne, U.; Weidner, S. M. MatrixAssisted Laser Desorption/Ionization Time-of-Flight Mass Spectrometric Imaging of Synthetic Polymer Sample Spots Prepared Using Ionic Liquid Matrices. Rapid Commun. Mass Spectrom. 2014, 28 (5), 489-498.

(91) Want, E. J.; Masson, P.; Michopoulos, F.; Wilson, I. D.; Theodoridis, G.; Plumb, R. S.; Shockcor, J.; Loftus, N.; Holmes, E.; Nicholson, J. K. Global Metabolic Profiling of Animal and Human Tissues via UPLC-MS. Nat. Protoc. 2013, 8 (1), 17-32.

(92) Meyer, G. M. J.; Maurer, H. H. Qualitative Metabolism Assessment and Toxicological Detection of Xylazine, a Veterinary Tranquilizer and Drug of Abuse, in Rat and Human Urine Using GC-MS, LC-MS n, and LC-HR-MS N. Anal. Bioanal. Chem. 2013, 405 (30), 9779-9789.

(93) Porpiglia, N.; Musile, G.; Bortolotti, F.; De Palo, E. F.; Tagliaro, F. Chiral Separation and Determination of Ketamine and Norketamine in Hair by Capillary Electrophoresis. Forensic Sci. Int. 2016, 266, 304-310.

(94) Jadoul, L.; Longuespée, R.; Noël, A.; De Pauw, E. A Spiked Tissue-Based Approach for Quantification of Phosphatidylcholines in Brain Section by MALDI Mass Spectrometry Imaging. Anal. Bioanal. Chem. 2015, 407 (8), 2095-2106.

(95) Barber, T. W.; Brockway, J. A.; Higgins, L. S. The Density of Tissues in and about the Head. Acta Neurol. Scand. 1970, 46 (1), 85-92.

(96) Lou, X.; De Waal, B. F. M.; Van Dongen, J. L. J.; Vekemans, J. A. J. M.; Meijer, E. W. A Pitfall of Using 2-[(2E)-3-(4-Tert-Butylphenyl)- 2-Methylprop-2Enylidene]Malononitrile as a Matrix in MALDI TOF MS: Chemical Adduction of Matrix to Analyte Amino Groups. J. Mass Spectrom. 2010, 45 (10), 1195-1202. 
2

3

4

5

6

7

8

9

10

11

12

13

14

15

16

17

18

19

20

21

22

23

24

25

26

27

28

29

30

31

32

33

34

35

36

37

38

39

40

41

42

43

44

45

46

47

48

49

50

51

52

53

54

55

56

57

58

59

60

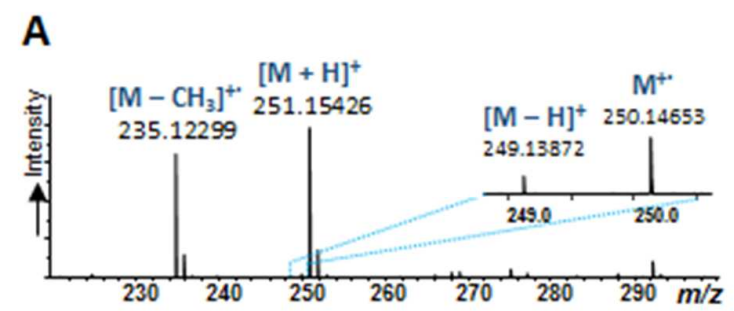

B

$\begin{array}{lcccc}\text { Compound } & \text { CHCA } & \text { DCTB } & \text { Xylazine } & \text { Ketamine } \\ \text { IE }[\mathrm{eV}] & 9.59 & 8.48 & 7.96 & 7.63 \\ \text { PA }[\mathrm{kJ} / \mathrm{moL}] & 863 & 866 & 1018 & 964\end{array}$

Figure 1. (A) Representative MALDI-FTICR mass spectrum of pure DCTB matrix after dried-droplet sample preparation. (B) Computationally-derived proton affinities (PA) and ionization energies (IE) for CHCA and DCTB matrices, as well the two CNS drugs (xylazine and ketamine). 

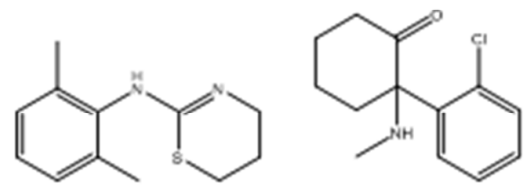

Xylazine

$\mathrm{M}_{\mathrm{t}}=220.33$

$\mathrm{p} K_{\mathrm{z}}=8.9$

$c \log D_{7.4}=1.06$
Ketamine

$M_{\mathrm{r}}=237.72$

$\mathrm{p} K_{2}=7.1$

$c \log D_{7.4}=2.07$

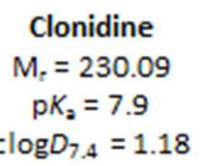

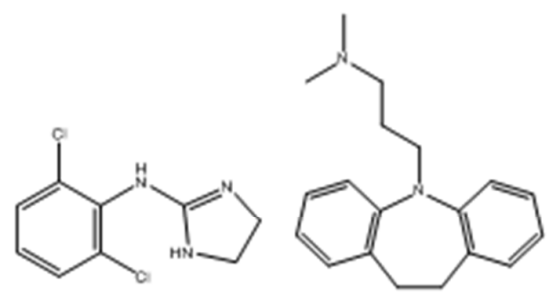

Imipramine

$\mathrm{M}_{\mathrm{r}}=280.41$

$\mathrm{p} K_{2}=9.2$

$\mathrm{c} \log D_{7.4}=2.68$

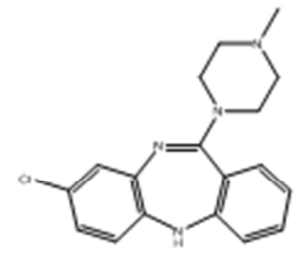

Clozapine

$M_{\mathrm{r}}=326.82$

$\mathrm{p} K_{\mathrm{a}}=7.8$

$c \log D_{7.4}=2.71$

Figure 2. Chemical structures of the five CNS drugs investigated in this study, along with molecular weights and calculated, $\mathrm{p} K_{\mathrm{a}}$ and $\operatorname{cog} D$ values (at physiological $\mathrm{pH}$ of 7.4). 
2

3

4

5

6

7

8

10
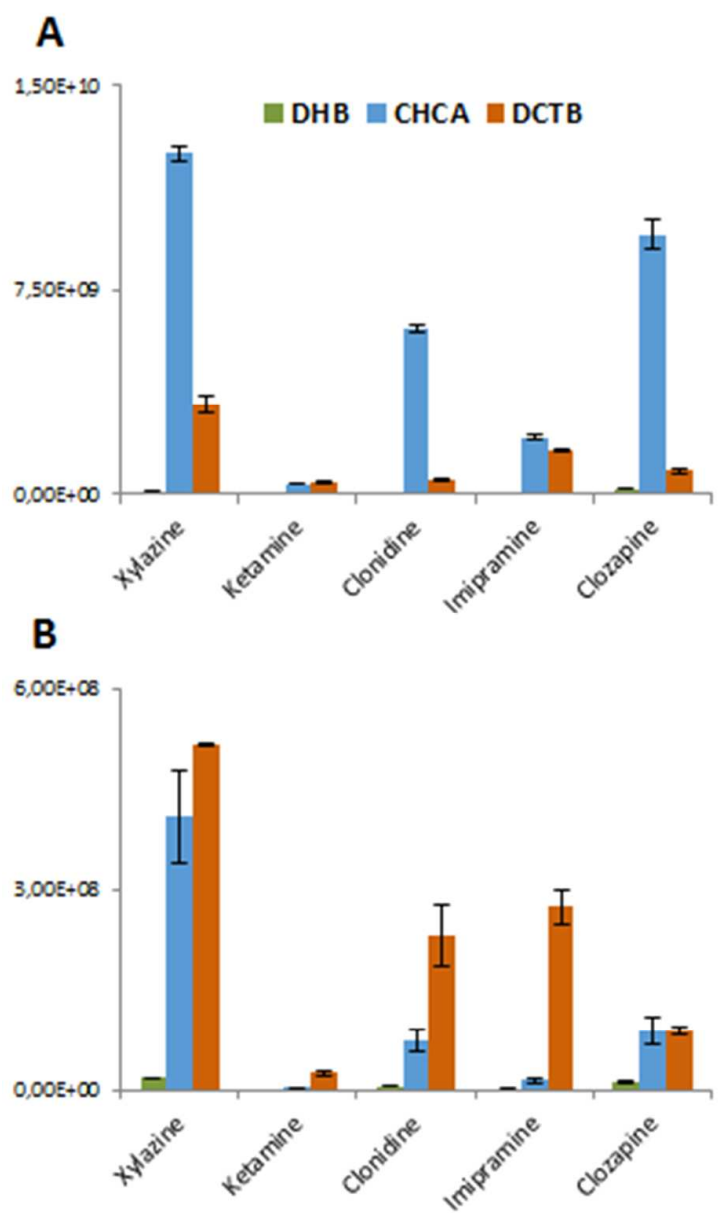

Figure 3. Bar chart showing signal intensities for (A) standard solutions of five CNS drugs obtained by MALDI-FTICR after dried-droplet sample preparation using DHB, CHCA and DCTB matrices; (B) standard solutions spiked into mouse brain extract. (Error bars represent standard deviation, SD $(n=3) ; 16$ transients from at least 3 different MALDI spots for interand intra-spot variability correction were collected of the individual drug standards $(10 \mu \mathrm{M})$ with dried-droplet sample preparation.) 


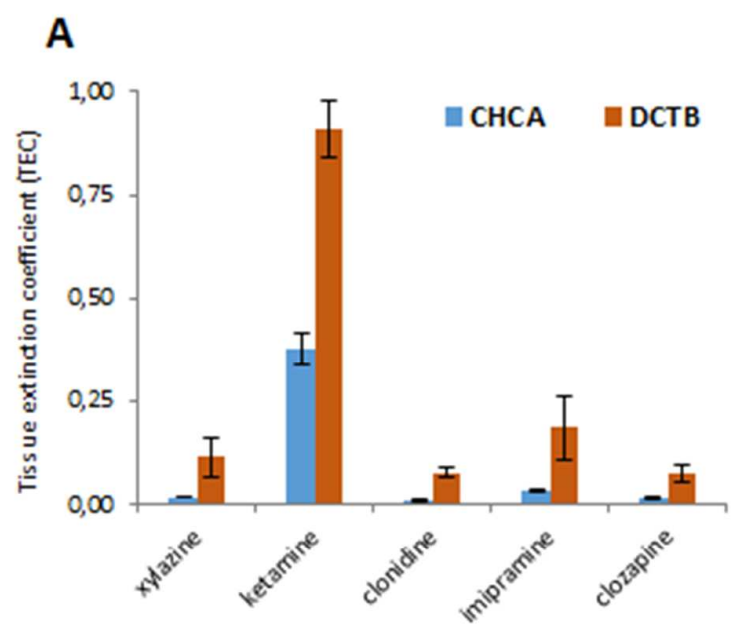

B

\begin{tabular}{ccc}
\multirow{2}{*}{ Compound } & Tissue extinction coefficient (TEC) \\
\cline { 2 - 3 } xylazine & CHCA & DCTB \\
ketamine & 0.02 & 0.11 \\
clonidine & 0.38 & 0.91 \\
imipramine & 0.01 & 0.08 \\
clozapine & 0.03 & 0.19 \\
& 0.02 & 0.07
\end{tabular}

Figure 4. Bar chart (A) and numerical values (B) of tissue extinction coefficients (TEC) calculated for five CNS drugs based on the MALDI-FTICR imaging experiments performed with CHCA and DCTB matrices. 


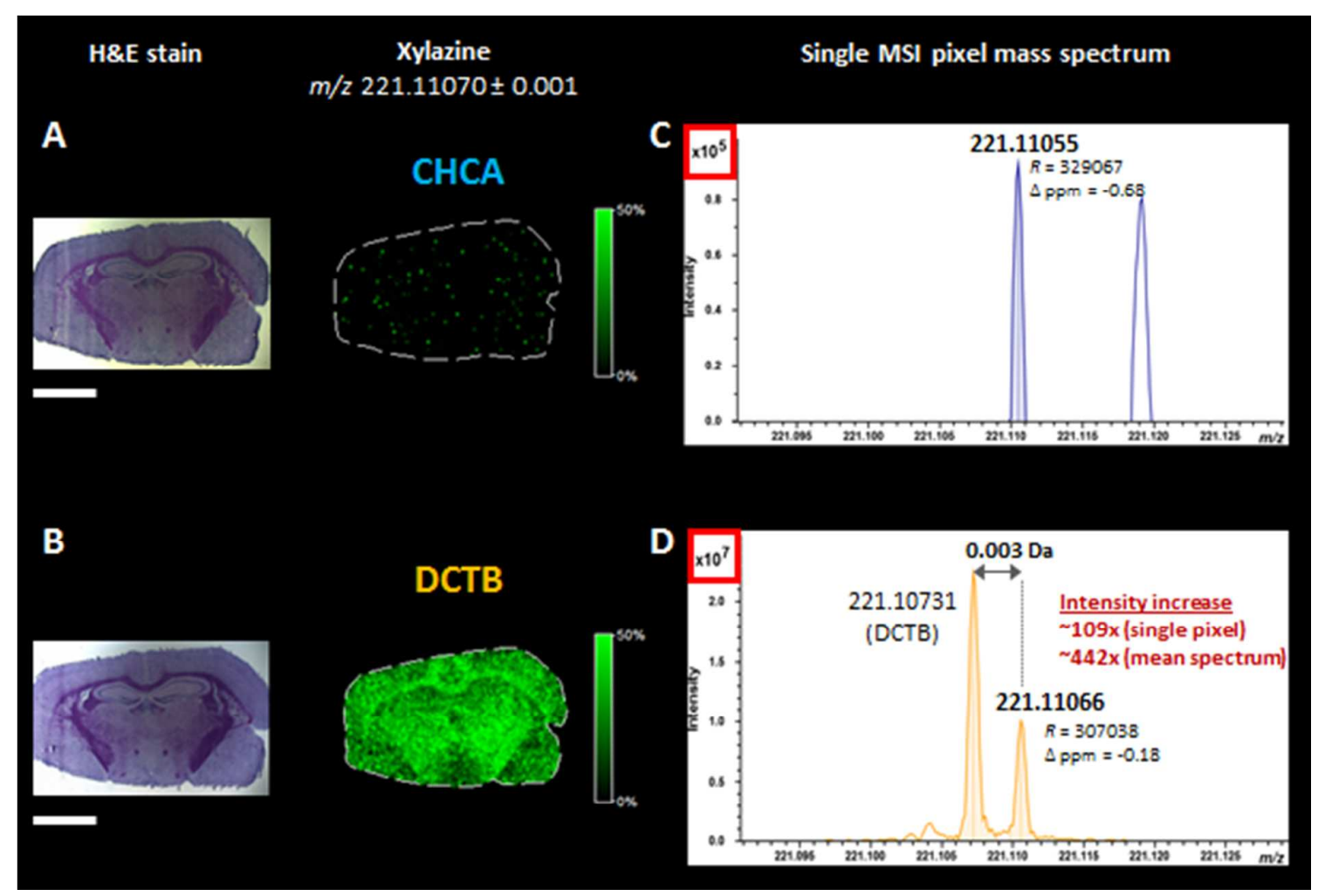

Figure 5. Spatial distribution of xylazine in mouse brain coronal sections obtained from MALDI-FTICR imaging experiments performed on two consecutive sections with two different MALDI matrices, CHCA (A) and DCTB (B), along with single MSI pixel mass spectra extracted from representative regions of the highest abundance of xylazine detected with CHCA (C) and DCTB (D). MSI pixel size: $100 \mu \mathrm{m}$. Scale bars: $2 \mathrm{~mm}$. 


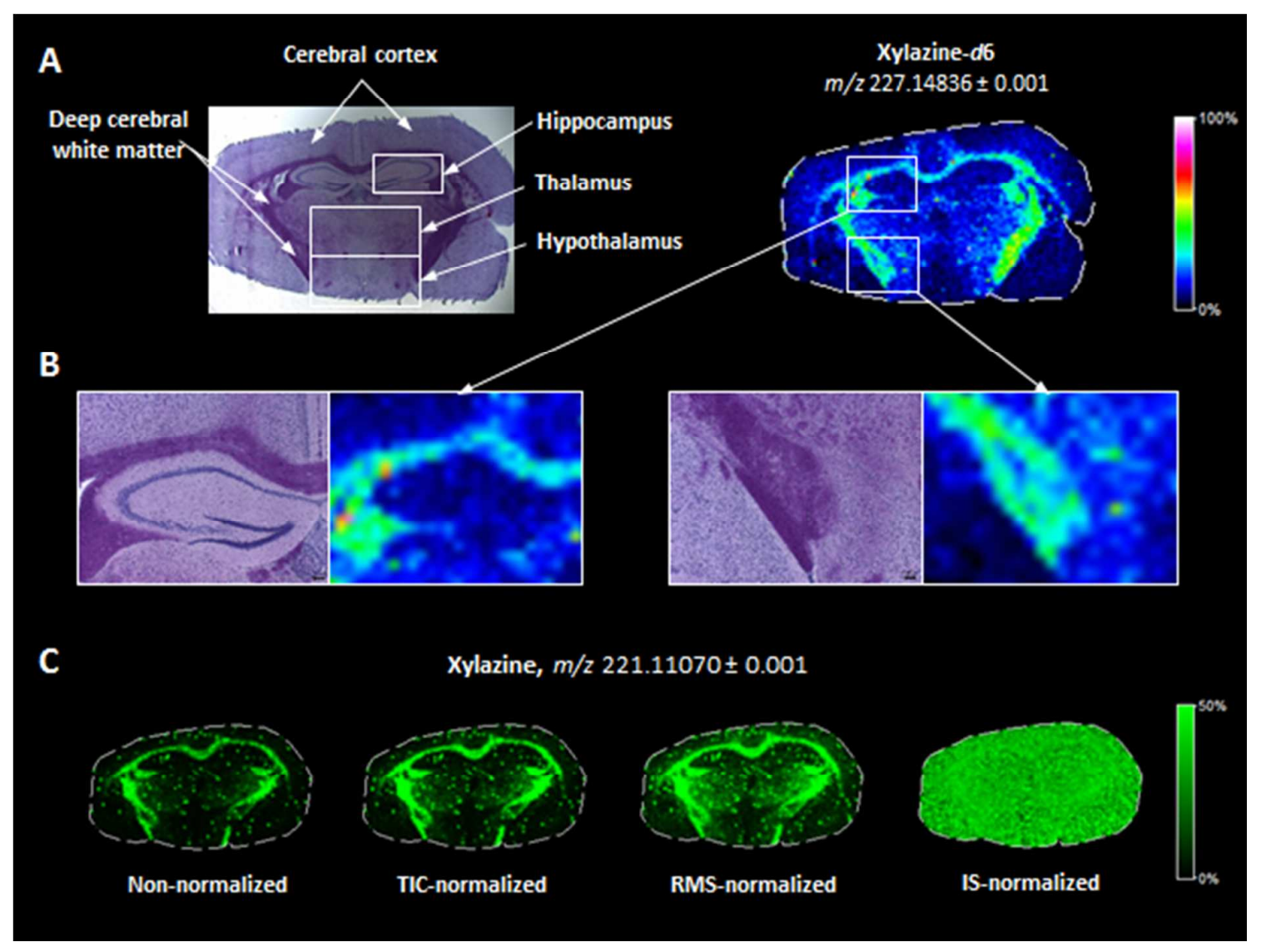

Figure 6. MS ion image (not normalized) of the evenly-distributed internal standard (xylazine- $d_{6}$ ) on brain coronal section obtained from xylazine-anesthetized mouse (A); two expanded sub-regions (hippocampus and deep cerebral white matter) (B) showing clear evidence for brain sub-region specific ion suppression of the deuterated drug signal. MSI pixel size: $100 \mu \mathrm{m}$. (C) MS ion images of the evenly-distributed xylazine standard on brain coronal section obtained from isoflurane-anesthetized mouse showing superior performance of normalization against isotope-labeled internal standard (IS) in comparison with two other common strategies (TIC and RMS). MSI pixel size: $100 \mu \mathrm{m}$. 


\section{For Table of Content (TOC) only}

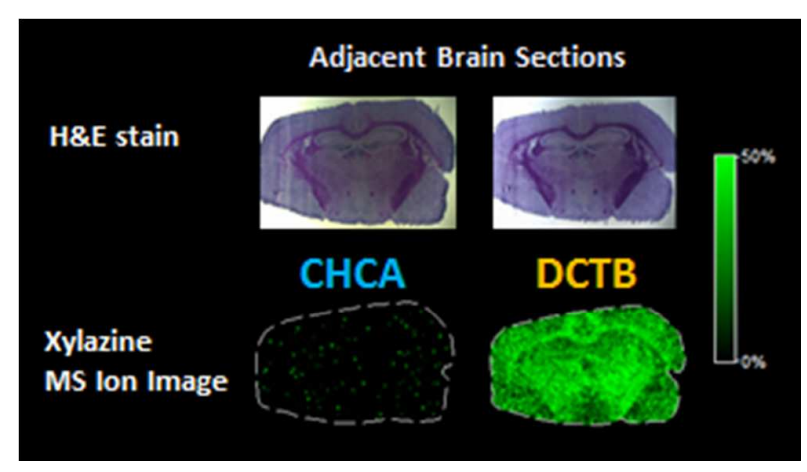

